\title{
Relato de Experiência: Círculos de Construção de Paz em uma Penitenciária Feminina
}

\author{
Luiza Rodrigues dos Santos ${ }^{1}$, Alcione Bastos Alves ${ }^{1}$ e Marilda \\ Castelar ${ }^{1}$ \\ ${ }^{1}$ Escola Bahiana de Medicina e Saúde Pública, Brasil | luizadossantos.pos@bahiana.edu.br; \\ alcionealves.pos@bahiana.edu.br; marildacastelar@bahiana.edu.br|https://orcid.org/0000- \\ 0002-9564-7733; https://orcid.org/0000-0001-7306-0053; https://orcid.org/0000-0003-1628-
}

\begin{abstract}
Resumo: Introdução: O texto objetiva conhecer o potencial dos Círculos de Construção de Paz para compreensão da importância da escuta na construção do lugar de fala de mulheres. Metodologia constitui-se em um relato de experiência partindo da vivência de uma das autoras, como facilitadora na condução de grupos com mulheres internas em uma penitenciária pública, utilizando a metodologia dos Círculos Resultados: revela-se a importância dessa experiência de trocas entre a facilitadora e as participantes da pesquisa para a construção e compreensão do lugar de fala a partir do lugar de escuta que a autora vivenciou, o que contribuiu para discussão do método dos círculos e o empoderamento de mulheres. Considerações finais: a dialogicidade que marca essa experiência de afetar e ser afetada pelo processo circular de contação de histórias entre mulheres com experiências de gênero diversas, motivou a busca de novas leituras críticas desencadeando processos de mudança das participantes.
\end{abstract}

Palavras-chave: Empoderamento; Mulheres; Círculos; Prisões.

The construction of the Place of Listening and Place of Speech by a Facilitator of Peacemaking Circles in a Women's Penitentiary

\begin{abstract}
Introduction: The text aims to understand the potential of the Peacebuilding Circle to understand the importance of listening in the construction of the place of speech of women. Methodology consists of an experience report based on the author's experience, as a facilitator in the conduct of groups with prisoner women in a public penitentiary, using the methodology of Circles. Results: this article demonstrates the importance of this experience of exchanges between the facilitator and the women, participants of the research, for the construction and understanding of the place of speech from the place of listening that the author experienced, which in the improvement and use of this helped for the empowerment of women. Final considerations: dialogicity marks this experience of affecting, but also be affected by the circular process of storytelling among women with diverse gender experiences, which contributed to the search for new critical readings triggering processes of change in the participants.
\end{abstract}

Keywords: Place of Speech; Listening Place; Qualified Listening; Coping Strategies; Empowerment; Women; Circular Technique.

\section{Introdução}

Para compreender o retrato do sistema carcerário feminino brasileiro, torna-se indispensável reconhecer os diversos lugares sociais das mulheres, como propõe a perspectiva crítico-política do feminismo negro. Esse posicionamento revela a compreensão da sobreposição de identidades sociais e como esta é elementar para a detecção das desigualdades provenientes de sistemas de opressão, os quais necessitam de atenção para o enfrentamento da violência no Brasil (Berth, 2019).

A autora Juliana Borges (2019) chama atenção para o fato de que, o encarceramento em massa da população negra representa muito mais que privação de liberdade. Em se tratando de mulheres negras, a autora reconhece a importância de debater a invisibilidade e a situação de extrema violência no cárcere, visto que as prisões dependem da violência para funcionarem, seja física, psicológica e simbólica, corroborados pelo ambiente perverso que nutre relacionamentos abusivos e opressões estruturais.

O encarceramento feminino revelou um aumento exponencial após o ano de 2006 quando inaugurada a Lei 13.343/2006 a qual institui o Sistema Nacional de Políticas Públicas sobre 
Drogas - Sisnad. Nessa ocasião, iniciou-se a chamada "guerras às drogas" no país. Esse marco destaca visivelmente o fenômeno do encarceramento feminino em massa.

Os dados estatísticos divulgados pelo Levantamento Nacional de Informações Penitenciárias revelam que, entre os anos de 2000 à 2016, a taxa de aprisionamento de mulheres aumentou em 455\% no país (Brasil, 2018).

Em relação às informações sobre a raça, cor ou etnia da população prisional feminina, o Relatório mencionado contemplou em sua pesquisa uma quantidade de 29.584 mulheres (o equivalente à $72 \%$ da população prisional feminina). A partir da análise dessa amostra, identificou-se que $62 \%$ da população prisional são mulheres negras (Brasil, 2018). Esse cenário destaca a necessidade de se pensar a política criminal a partir das vulnerabilidades de mulheres que, na grande maioria foram presas por tráfico. É inegável os impactos que essa política acarreta o aumento da população carcerária e, especificamente, de mulheres negras e pobres no país.

Dada essa realidade, os círculos realizados na unidade prisional feminina eram formados por grupos de mulheres, em sua maioria, negras (pretas e pardas), por isto o destaque para as epistemologias feministas para análise da experiência vivida, considerando o processo de reflexividade característico das pesquisas feministas. Esse relato de experiência contempla uma análise dos atravessamentos subjetivos frente a pesquisa e a prática da facilitadora, implicada no campo da pesquisa, a partir dos efeitos da escuta qualificada no seu processo de conscientização racial e a sua autopercepção identitária como mulher negra.

Diante de todas as contradições e desigualdades de gênero, raça e classe nesse contexto, percebeu-se a urgência de ampliação de espaços para promoção de escuta coletiva das internas sobre as suas necessidades. Assim, a experiência objeto de estudo deste relato configura-se no exercício de facilitação de Círculos de Construção de Paz com as mulheres condenadas ao regime fechado em uma Penitenciária Feminina, realizados ao longo dos anos de 2019 e 2020. Foram adotadas as modalidades de Círculo de Diálogo, Círculos de Apoio, Círculos de Reflexão que ocorreram presencial e virtualmente. Este artigo pretendeu conhecer o potencial dos Círculos de Construção de Paz para compreensão da importância da escuta na construção do lugar de fala de mulheres. Para assim impulsionar o empoderamento feminino a partir da troca de experiências entre mulheres.

Considerando o potencial transformador decorrentes das interações entre participantes e pesquisadora permitida pelo processo dialógico de investigação feminista. Essa postura crítica e reflexiva agrega-se também ao pensamento do advogado, filósofo e professor universitário, Silvio Luiz de Almeida (2019) acerca da necessidade do compromisso ético da academia e das instituições de um modo geral contra o racismo estrutural. Violência reproduzida pelas instituições e sociedade, de forma explícita ou de micro agressões, como piadas, silenciamento, isolamento, dentre outras formas.

A escritora e psicóloga Grada Kilomba (2019) ao tratar sobre o racismo genderizado, explica que as mulheres negras têm sido incluídas em discursos que não interpretam as suas realidades, pois suas experiências são invisibilizadas dentro dos debates sobre gênero. Estas adotam como referencial a experiência da mulher branca criada pela falsa ideia de sororidade universal. Nos debates sobre raça, as mulheres negras são também excluídas, pois referem-se à experiência exclusiva do homem negro, assim como dos debates sobre classe no qual raça se quer tem lugar. Logo, para o enfrentamento da violência é preciso que haja a articulação das diversas formas de racismos existentes.

Há nas pesquisas feministas, o enfoque na preocupação com o lugar que a pesquisadora ocupa na relação com as participantes da pesquisa, assim como o impacto do processo investigativo em suas vidas (Narvaz \& Koller, 2006). Logo, a investigação busca articularse ao movimento político feminista, a partir da perspectiva interseccional, de modo a reduzir os vieses sexistas, racistas e classistas das produções do saber, característico das metodologias tradicionais da ciência heteropatriarcal, as quais pressupõem a legitimação ou justificativa de situações de subalternidade de mulheres (Akotirene, 2019). 
Essa perspectiva visa amparar a análise crítica sobre as ideias e ações de mudança social, especialmente, no que se refere ao potencial dos círculos para a promoção da autonomia e a superação de desigualdade de poder em que as mulheres negras se encontram.

Em uma sociedade que não é nivelada na dimensão pragmática ou material e de condições direitos básicos, ela é sim excludente, pois o poder e o dinheiro, assim como o descaso e descompromisso ético fracassam constantemente a concretização do ideal de Justiça. Isto é, de garantia direitos no âmbito da manutenção da Norma, da Ordem social, do Estado Democrático de Direito (Pelizzoli, 2014). Desse modo, percebeu-se como as práticas restaurativas podem simbolizar a minimização do poder absoluto do Estado no exercício de punição ampla, durante a execução da pena privativa de liberdade, visando a construção de uma cultura antipunitivista.

A Justiça Restaurativa no Brasil não foi implementada como modelo substitutivo ao modelo tradicional de justiça punitivista, na prática, incorpora timidamente técnicas restaurativas em busca da promoção de uma cultura de paz (Miranda \& Lopes, 2019). Por meio da reunião ordenada de princípios, procedimentos e ações da Justiça Restaurativa, os círculos realizados com mulheres em uma penitenciária feminina, convida à reflexão e à conscientização sobre os temas trabalhados. Assim, busca-se promover um espaço de diálogo para contribuir para o empoderamento das mulheres em face das violências sofridas e praticadas na prisão.

Essa vertente das práticas restaurativas tem origem ancestral e cultural inspirada nos povos originários norte americanos e canadenses. Essa prática foi sistematizada pela autora canadense Kay Pranis (2019) e baseia-se nos princípios da Resolução 225/2016 do Conselho Nacional de Justiça, que dispõe sobre a Política Nacional de Justiça Restaurativa no âmbito do Poder Judiciário. Essa método de diálogo se assemelha ao Círculo de Cultura de Paulo Freire (2013), considerando que ambos buscam a reelaboração do contexto social através do diálogo, em que os participantes expõem voluntariamente seus sentimentos e opiniões sobre si, sobre as suas vivências, sobre aquilo que the afeta e sobre o mundo. Assim, a contação de histórias possibilita a internalização do aprendizado a partir da escuta de si e do outro, mediada por um facilitador que conduz as dinâmicas entre os participantes (Dantas \& Linhares, 2014).

\section{Metodologia}

Este artigo é um relato de experiência (RE) sobre o uso dos Círculos de Construção de Paz em uma unidade prisional feminina. Esta pesquisa originou-se de uma pesquisa maior intitulada Processos Psicossociais na Construção de Estratégias de Enfrentamento da Violência para Garantia de Direitos, aprovada pelo Comitê de Ética da Escola Bahiana de Medicina e Saúde Pública, em 05/05/2020, sob o número do CAAE: 28706920.1.0000.5544.

O método de relato de experiência foi escolhido por possibilitar a inclusão da subjetividade de quem escreve e refere-se a uma construção teórico-prática que possibilita, por meio de diferentes perspectivas epistemológicas, uma análise sobre a experiência em si, a partir do olhar da pesquisadora inserida em um determinado contexto cultural e histórico (Daltro \& Faria, 2019). Para essa construção, utilizou-se métodos observacionais com o apoio do caderno de campo para o aprofundamento das reflexões da prática da facilitadora.

Assim, o RE é uma modalidade de cultivo de conhecimento que se insere no território da pesquisa qualitativa, através da memória, na qual a pesquisadora se encontra implicada (Daltro \& Faria, 2019). A escolha deste método justifica-se em razão do RE permitir a apreensão das subjetividades femininas dos coletivos e do campo de pesquisa. Em paralelo, as leituras das epistemologias feministas impulsionaram a ruptura da neutralidade e isenção em face do processo de investigação e da análise dos resultados, pois esse campo epistêmico contribui para a defesa de formas inovadoras de ler e construir a realidade e discursos dos seus múltiplos agentes (Neves \& Nogueira, 2005). 
Nesse sentido, considera-se o propósito questionador da investigação acerca da questão apresentada, o empoderamento feminino. Assim, busca-se analisar este relato de experiência a partir do referencial teórico epistemológico feminista, de modo a romper com a predominância do racionalismo científico na produção do conhecimento, que objetiva encontrar a verdade e o universalismo (Schimanski, et al., 2017).

A produção do conhecimento a partir deste método é relativo a um contexto social e histórico específico e revela-se como um conhecimento dialógico porque está permeado por múltiplas experiências, vozes e autorias de mulheres, em sua maioria negras.

Nota-se que tais pesquisas envolvem uma preocupação com todo o processo de condução da investigação, que se inicia com a escolha do delineamento do desenho de estudo a ser utilizado, uma vez que diferentes métodos conduzem a diferentes resultados. Dessa forma, os pressupostos epistemológicos, metodológicos, ontológicos e éticos, implícitos ou explícitos nos delineamentos de pesquisa, refletem implicações políticas, podendo estar a serviço de diferentes interesses, de forma direta ou indireta (Narvaz \& Koller, 2006).

A autonomia de pesquisadoras feministas possibilita a experiência da reflexividade na pesquisa qualitativa (Neves \& Nogueira, 2005) e representa, em si, um caminho para a reelaboração mental e reconstrução dos sentidos construídos ao longo da vida sobre os modos de viver e ser mulher. Desse modo, esse estudo visa compreender os processos de violências na vida de mulheres para a construção do pensamento crítico de práticas que não contribuam para o enfrentamento de opressões sistêmicas, institucionais e a garantia de direitos humanos.

Essa reflexão crítica durante o processo de construção do conhecimento acerca das próprias experiências da pesquisadora, das suas práticas profissionais como facilitadora e a sua influência na realização do estudo revela a importância de implicar-se no processo de escrita da pesquisa. Dessa forma, nega-se a neutralidade e objetividade proveniente do caráter androcêntrico das metodologias positivistas que, na maioria das vezes, reforçam teses e ideias que culpabilizam mulheres envolvidas em contextos de violência.

A prática da facilitadora articulou-se à construção do seu pensamento crítico científico, consolidado a partir da leitura do pensamento de autoras negras e, majoritariamente, afrolatino-americanas, que vêm trazendo a importância da consciência acerca do lugar de fala, de modo a contribuir com a luta antirracista, antissexista e anti-LGBTfóbica. Assim, a autora Djamila Ribeiro (2019, p.69), em sua obra Lugar de Fala, afirma que lugar social não determina uma consciência discursiva sobre esse lugar, contudo, as experiências diversas de gênero são demarcadas a partir do lugar que ocupamos socialmente. De acordo com a autora, ao promover uma multiplicidade de vozes o que se pretende, sobretudo, é quebrar com o discurso autorizado único e pretensamente universal. Portanto, busca-se lutar para romper com o regime de autorização discursiva.

Nesse sentido, somente após o processo de internalização da desconstrução de padrões que reforçam violências contra a mulher que se consolidou por meio desse lugar de escuta, é que se tornou possível escrever esse relato. Sobretudo porque ele também convoca a pesquisadora para olhar para a realidade dessa experiência interna e externa diante dos efeitos ressoados na facilitadora pela sua prática.

Os encontros ocorreram no período de 2019 presencialmente e foram organizados por volta de 5 grupos de 10 a 15 mulheres, no máximo, contemplando a maioria das mulheres da unidade. Em 2020, os círculos passaram a ocorrer na modalidade online e eram feitos em grupos de 5 mulheres, respeitando os protocolos de biossegurança, como o distanciamento mínimo entre as participantes e o uso obrigatório de máscaras. Ocorreram em média, 1 círculo por mês, totalizando 10 encontros.

Durante a coleta dos dados acerca da experiência vivida pela facilitadora, foi utilizado Diário de Campo como instrumento, para registrar as anotações pessoais da pesquisadora que contemplam as suas percepções sobre o desenvolvimento desse trabalho em relação ao lugar de escuta e lugar de fala da facilitadora, o seu processo de identificação racial e as dificuldades enfrentadas. Em relação às informações registradas, destaca-se que as mulheres em situação de privação de liberdade não foram abordadas diretamente nos 
círculos sobre os efeitos da experiência da sua participação. Também não foram registrados os conteúdos abordados durante a realização desse trabalho, visto que os círculos não são métodos de investigação. Além disso, não foram evidenciados quaisquer dados que pudessem identificá-las.

Os registros compõem a documentação da memória do cotidiano e do processamento da experiência para a descrição dos atravessamentos subjetivos da facilitadora, da metodologia e recursos utilizados nos círculos para somar à análise dos dados

No que concerne a prática vivenciada dos círculos de construção de paz, já adotada pelo Poder Judiciário brasileiro, caracteriza-se por uma estrutura de diálogo em grupo que promove foco, responsabilidade, inclusão e conexão entre os participantes, ocorre por meio do processo da contação de histórias de experiências (Pranis, 2019). São conduzidos a partir de um roteiro elaborado previamente pelas facilitadoras que organizam as dinâmicas, a exposição de vídeos, a utilização de recursos musicais e artísticos que simbolizam aspectos profundos ligados aos princípios éticos da Justiça Restaurativa, como: corresponsabilidade, o empoderamento, a conexão e inclusão, dentre outros dispostos no artigo $2^{\circ}$ da Resolução 225/2016 do Conselho Nacional de Justiça.

Para as autoras Carolyn Boyes-Watson e Kay Pranis (2011) as participantes em um círculo desempenham um papel principal na construção dos valores do grupo relativos às suas vidas pessoais, comunitárias, relacionais e simbólicas. Essa etapa é importante para estabelecer um espaço seguro para a fala e contribui para o fortalecimento da coesão entre as participantes (Pezzoli, 2014). Após essa etapa, inicia-se a construção das diretrizes que articulam os acordos entre as integrantes do grupo sobre o modo de condução do círculo, portanto, descrevem os comportamentos que deixarão o espaço seguro para que falem. A clareza das normas e combinados inibem a expressão de atitudes que venham a desrespeitar alguma participante (Pranis \& Boyes, 2011).

\section{Discussão dos Resultados}

O Diário de Campo contém informações acerca do planejamento, das dificuldades de execução desse trabalho, considerando as limitações determinadas pelo funcionamento da instituição e o território para o estabelecimento das dinâmicas, as possibilidades e limites da prática, levando em conta os aspectos característicos do ambiente carcerário. Assim, tornou-se fundamental observar algumas peculiaridades locais para preservar a segurança dessas mulheres, criando grupos menores para não reforçar disputas, brigas ou discriminações entre as participantes, evitando não expor aquelas que sofrem violências dentro desse contexto e a potencialização dos conflitos deste ambiente.

Antes de iniciar o trabalho, estabeleceu-se um contrato tácito entre as participantes de cada grupo em relação a voluntariedade para participar do círculo e a confidencialidade no que tange às histórias compartilhadas. Ademais, combinou-se o horário de início, tempo de duração e esclareceu-se sobre a importância do cuidado com o julgamento pessoal das falas das outras participantes.

Nesse sentido, os círculos realizados foram da modalidade não-conflitivo, considerando as necessidades apresentadas pelas próprias internas. Os temas facilitados foram: autocuidado; a consciência negra; acolhimento em tempos de pandemia; o luto; a maternidade; saudade; cuidados com a saúde; responsabilidade pelos nossos direitos e direitos das outras; empoderamento feminino; liberdade e responsabilidade.

No início da atividade utilizou-se recursos de objetos que representavam elementos interculturais para compor os chamados "centros dos círculos", que funcionam como estímulos disparadores para o início dos diálogos. Na modalidade virtual em 2020, estes recursos foram compostos por imagens impressas relacionadas aos temas trabalhados. Também foi utilizado o objeto da palavra, que simboliza o poder da fala e da escuta ativa no círculo (Boyes-Watson \& Pranis, 2011), o qual era repassado entre as participantes no modo presencial durante a contação de histórias. 
Após o trabalho do grupo, as mulheres enfatizaram que se sentiram acolhidas e ouvidas nos círculos, todavia também revelaram que a atividade não era suficiente para superar a sua dor, o que evidencia a necessidade de mais atividades grupais e do acompanhamento psicossocial constante nesse ambiente para o cuidado da saúde mental dessas mulheres.

A experiência relatada apresentou-se como uma possível estratégia de enfrentamento das violências psicológica, institucional, física, dentre outras. Da mesma forma, funcionou como um espaço de garantia de direitos das mulheres encarceradas. Desse modo, foi observado que as práticas restaurativas podem contribuir para limitar o exercício do poder de punição absoluto do Estado, durante a execução da pena privativa de liberdade, para que não sejam cometidas arbitrariedades ilegais, tanto por omissões ou violações de direitos.

Percebeu-se que as perguntas elaboradas para trabalhar os temas específicos, muitas vezes, não conectava às reais necessidades das internas que utilizavam o espaço para buscar resolver questões imediatas relacionadas ao contexto vivenciado pela luta dos seus direitos. Isto denuncia a urgência de criação de novos espaços de diálogos coletivos para união dessas reivindicações por meio de uma escuta qualificada. Por essa limitação, os círculos acabaram sendo direcionados para outros fins, dificultando a promoção da reflexão e da responsabilização em razão da precarização estatal dos direitos demandados.

Como resultado dessa prática, utilizando a perspectiva da autora Joice Berth $(2019$, p.18), foi possível observar que o empoderamento feminino desenvolveu-se a partir do aspecto político, em razão da consciência do grupo das desigualdades de poder e pela mobilização e organização das mulheres para a luta coletiva pelos seus direitos. De acordo com a autora, o empoderamento é um instrumento de emancipação política e social que não deve servir para "viciar" ou criar relações paternalistas, assistencialistas ou de dependência entre indivíduos.

Considerando a importância do lugar de fala, de acordo com os registros de campo, percebeu-se que é essencial se manter um diálogo horizontalizado, sem a predominância do desequilíbrio das relações, em razão da hierarquia entre a facilitadora e as participantes, de modo que não haja constrangimento para responder as perguntas ou que as narrativas não se tornem enviesadas, desvirtuando, assim, a finalidade do círculo ou artificializado o processo circular.

De acordo com Pelizzoli (2014, p. 435) quando alguns militantes ou críticos de base social, marxista ou não, encontram propostas que operam com ações psicossociais, como aquelas que estabelecem o nível do diálogo, humanização, resgate de intersubjetividade, mudanças interpessoais e similares, há a tendência de encarar essas ações como menores, subjetivas, ou até mesmo espirituais, "apenas psicológicas". As mudanças estruturais são fundamentais para uma sociedade mais justa e igualitária, no entanto, não é possível apenas esperar por condições econômicas ideais às classes desfavorecidas, para se buscar outras estratégias de enfrentamento às violências.

Muitos limites ainda devem ser superados no processo de transformação desse cenário, pois para que haja o empoderamento é preciso enfrentar opressões estruturais que são reproduzidas pela política de encarceramento em massa. Para haver mudança, é essencial a participação e a mobilização de todos na construção de novas estratégias e soluções. Mas, inegavelmente, a ampliação de espaços de diálogos coletivos configura dispositivos da produção do cuidado que não podem ser negados no cárcere.

Uma outra face do empoderamento feminino se revelou pelo processo de resgate da subjetividade por meio da contação da história de vida da facilitadora, proporcionada pela potência do encontro com mulheres nos círculos e articulada aos conhecimentos das epistemologias feministas negras. Esse processo impulsionou interpretações críticas da realidade vivida e contribuiu para a construção do lugar de fala da facilitadora. A autopercepção identitária, estimulada crítica e politicamente por essas vivências, passou pelo processo de identificação da sua negritude, a partir da consciência racial, a qual foi negada durante muito tempo em sua vida pelo processo histórico de miscigenação da população brasileira que Ihe atravessou. Portanto, a transformação vivenciada apresenta 
o potencial do uso da metodologia dos círculos para o empoderamento de mulheres envolvidas em processos de violências em suas vidas.

Esta discussão é importante para o tema pesquisado, o empoderamento feminino, pois os círculos de diálogo, ou círculos da Justiça Restaurativa atuam no sentido primeiro da Justiça, isto é, sob uma perspectiva cidadã, de inclusão dos sujeitos no sentido maior da sociabilidade, ou comunidade. Assim, as ferramentas sociais ou psicossociais circulares, sistêmicas, comunitárias, são instrumentos pedagógicos efetivos, capazes de promover a conscientização, a união de grupos, a formação para iniciativas sociais e a inclusão social (Pelizzoli, 2014). Todavia, não se ignora a importância das políticas públicas para a reformulação do atual modelo penal punitivista, que reforça o encarceramento em massa da população negra, pois essas políticas são essenciais para o enfrentamento da violência racial estrutural nesse contexto.

\section{Conclusões}

Ao colocar em diálogo essa vivência com as epistemologias feministas, foi possível ressignificar as práticas, para analisar a experiência de facilitação de afetar, mas também ser afetada pelo processo circular de contação de histórias entre mulheres com experiências de gênero diversas, em um processo dialético constante. A escuta qualificada com interação humanizada, cidadã e solidária vivenciada nos círculos contribuiu para a construção de um espaço de atenção às necessidades e aos direitos das participantes que eram demandados, seja de ordem jurídica, assistencial, de saúde psíquica ou física. Esta foi uma ferramenta valiosa para a atuação prática de facilitadoras nos presídios, bem como poderá ser utilizada por outros profissionais que promovem o cuidado no Judiciário.

Portanto, trata-se de mais uma forma de materialização do princípio constitucional de acesso à justiça previsto na constituição federal brasileira de 1988 (CRFB/88). Além disso, os círculos se configuram nesse ambiente como um espaço para garantia de direitos dispostos na lei 7.210, de 11 de julho de 1984 - Lei de Execução Penal, a saber: direito à saúde, proporcionalidade na distribuição do tempo para o trabalho, o descanso e a recreação, exercício das atividades intelectuais e artísticas.

Através de uma imersão no campo, foi possível analisar a influência dos processos circulares no empoderamento de mulheres. A observação se destacou, neste contexto, como um empreendimento dialógico que envolveu os conflitos, tensionamentos e as complexidades em relação às reflexões teóricas e práticas da facilitadora, principalmente em relação ao acolhimento, à escuta e mobilizações provocadas pela participação nos círculos. Essa experiência atravessou a facilitadora de forma relacional porque por meio da análise do RE foi possível compreender que é a partir da visão sobre si e sobre o mundo, que se relaciona com o outro. Conclui-se que a escuta qualificada, por meio da relação dialética, é ferramenta indispensável na construção de lugares de fala das mulheres dentro do círculo.

\section{Referências}

Associação dos Magistrados Brasileiros (AMB). (2015). Justiça Restaurativa do Brasil: a paz pede a palavra. Cartilha. https://www.amb.com.br/jr/docs/cartilha.pdf

Almeida, S. (2019). Racismo Estrutural (Feminismos Plurais). Pólen Livros.

Beth, J. (2019). Empoderamento (Feminismos Plurais). Pólen Livros.

Borges, J. (2019). Encarceramento em massa (Feminismos Plurais). Pólen Livros

Brasil, Conselho Nacional de Justiça. (2015). Resolução no 225: dispõe sobre a Política. https://atos.cnj.jus.br/atos/detalhar/2289

Brasil, Conselho Nacional de Justiça. (2019). Mapeamento dos Programas de Justiça Restaurativa. Seminário de Justiça Restaurativa. https://atos.cnj.jus.br/atos/detalhar/2289 
Brasil (1988). Constituição da República Federativa do Brasil http://www.planalto.gov.br/ccivil_03/constituicao/constituicaocompilado.htm>

Brasil, (2006). Lei № 11.343, de 23 de agosto- Sistema Nacional de Políticas Públicas sobre Drogas - Sisnad. http://www.planalto.gov.br/ccivil_03/_Ato2004-2006/2006/Lei/L11343.htm

Brasil, Lei 7.210, de 11 de julho de (1984) - Lei de Execução Penal. http://www.planalto.gov.br/ccivil_03/leis//7210.htm

Brasil, Ministério da Justiça e da Segurança Pública Departamento Penitenciário Nacional. (2018). Levantamento Nacional de Informações Penitenciárias INFOPEN Mulheres. http://depen.gov.br/DEPEN/depen/sisdepen/infopen-mulheres/infopen-mulheres

Daltro, M. R., \& Faria, A. A. (2019). Relato de experiência: Uma narrativa científica na pósmodernidade. Estudos e Pesquisas em Psicologia, 19(1), 223-237. http://pepsic.bvsalud.org/scielo.php?script=sci_arttext\&pid=S180842812019000100013\&lng=pt\&tlng=pt.

Dantas, V. L. Linhares, A. M. B. (2014). Círculos de Cultura: problematização da realidade e protagonismo popular. I/ Caderno de educação popular em saúde / Ministério da Saúde, Secretaria de Gestão Estratégica e Participativa. Departamento de Apoio à Gestão Participativa. - Brasília: Ministério da Saúde, p.74-

78http://bvsms.saude.gov.br/bvs/publicacoes/2_caderno_educacao_popular_saude.pdf.

Freire, P. (2013) Pedagogia do Oprimido. 1ำ ed (eBook). São Paulo: Editora Paz e Terra, S/A.Harding, S. (1987). Feminismo e Methodologia. Indiana University Press.

Kilomba, G. (2019). Memórias da plantação: episódios de racismo cotidiano. Trad. Jess Oliveira. 1. Ed. Rio de Janeiro: COBOGÓ

Miranda, D. M., Lopes, D. F. (2019) Do ciclo do crime ao círculo de paz: a aplicabilidade dos círculos restaurativos em unidades prisionais. Vertentes do Direito. Vol. 06, n. 1. ISSN no 2350106. https://sistemas.uft.edu.br/periodicos/index.php/direito/article/view/6855/15299.

Narvaz, M. G., \& Koller, S.H. (2006). Metodologias feministas e estudos de gênero: articulando pesquisa, clínica e política. Psicologia em Estudo, 11(3), 647-

654. https://dx.doi.org/10.1590/S1413-73722006000300021.

https://www.scielo.br/j/pe/a/NGxfm9MK4wBdpJ7twQzvfYM/abstract/?lang=pt >

Neves, S. \& Nogueira, C. (2005). Metodologias feministas: a reflexividade ao serviço da investigação nas ciências sociais. Psicologia: Reflexão e Crítica, 18(3), 408-412. https://doi.org/10.1590/S0102-79722005000300015.

https://www.scielo.br/j/prc/a/ZMkjGGcWRPMvKLFWZ94xfHf/?format=pdf\&lang=pt.

Nogueira, I., P. (2017). Lugar de fala, lugar de escuta: criação sonora e performance em diálogo com a pesquisa artística e com as epistemologias feministas. Revista Vórtex, v.5, n.2. p.1-20.

Pelizzoli, M. L. (2014). Círculos de Diálogo: Base Restaurativa para a Justiça e os Direitos Humanos Silva, Eduardo F., Gediel, José A. P. Trauczynski, Silvia C. (orgs) Direitos humanos e políticas públicas. Universidade Positivo. p. 432.

Pranis, K. (2017). Processos Circulares de Construção de Paz. Tradução Tônia Van. 1aㅡ. Ed. Palas Athenas.

Pranis, K. \& Boyes-Watson, C. (2011) No coração da esperança. Guia de práticas restaurativas. TJERS/AJURIS. https://crianca.mppr.mp.br/arquivos/File/publi/tdhbrasil/

guia_de_praticas_circulares_no_coracao_da_esperanca.pdf.

Raimundo, Jader Sebastião, Cadete, Matilde Meire Miranda. (2012). Escuta qualificada e gestão social entre os profissionais de saúde. Acta Paulista de Enfermagem, 25(spe2), 6167. https://doi.org/10.1590/S0103-21002012000900010

Ribeiro, D. (2019). Lugar de Fala (Feminismos Plurais). Pólen Livros.

Schimanski, E., Pereira, M. C \& Paula E. F. (2017) Epistemologia Feminista e Ciências Sociais. Las encrucijadas abiertas de América Latina La Sociologia en tiempos de cambio. XXXI Congresso Alas, Uruguay. https://www.easyplanners.net/alas2017/opc/tl/5585_edina_schimanski.pdf 